\title{
The evolution of endovascular treatment for intracranial arteriovenous malformations
}

\author{
Ruth E. Bristol, M.D., Felipe C. Albuquerque, M.D., \\ and Cameron G. MCDougall, M.D.
}

\author{
Division of Neurological Surgery, Barrow Neurological Institute, St. Joseph's Hospital and Medical \\ Center, Phoenix, Arizona
}

\begin{abstract}
$\checkmark \quad$ Endovascular therapy for arteriovenous malformations (AVMs) remains a relatively new approach. Beginning in the 1960s with the use of flow-directed techniques for selective embolization, hemodynamic alterations have been used to treat these lesions. In every aspect of treatment, technological advances, including catheters, embolic materials, angiography suites, and pharmacological agents, have improved outcomes while lowering the risk to patients.

In this article, the authors review the technical evolution of endovascular AVM therapy. Developments in embolic materials, beginning with foreign bodies and autografts and continuing through to highly engineered contemporary substances, are discussed. Finally, changes in treatment paradigms that have occurred over the years are traced. Within neurosurgery, this specialty has shown some of the fastest growth and development in recent decades. As minimally invasive approaches are embraced in all areas of medicine, it is clear that this treatment modality will continue to be refined.
\end{abstract}

\section{KEY WORDS • arteriovenous malformation • endovascular therapy • embolic agent • history of neurosurgery}

$\mathrm{I}$ $\mathrm{T}$ is difficult to say precisely when endovascular neurosurgery began. As Dr. Charles Kerber eloquently describes in "Personal Accounts of the Evolution" (Kerber $\mathrm{C}$, personal communication, 2006), surgeons at the turn of the twentieth century were aware of the potential therapeutic utility of intracranial blood flow. Major, mainstream developments in endovascular treatment for intracranial AVMs began in the early 1960s. Although a muscle plug embolus was intentionally introduced through the ICA in 1930, ${ }^{23}$ it was many years before endovascular treatment for any intracranial pathological condition gained popularity. Luessenhop and Spence ${ }^{20}$ first reported the concept of using enlarged, abnormal feeding arteries for direct embolization. This method was initially described as "artificial embolization," and they planned to use the smaller nidus vessels to block penetration of embolic material and therefore occlude proximal feeding vessels. This concept is still integral to today's technology. Much of the pioneering work on embolic agents focused on the occlusion of aneurysms. Electrothrombosis as well as balloon and coil occlusion were all first used to treat saccular aneurysms, but these techniques have also

\footnotetext{
Abbreviations used in this paper: AVM = arteriovenous malformation; IBCA = isobutyl 2-cyanoacrylate; ICA = internal carotid artery; NBCA $=N$-butyl cyanoacrylate; PVA = polyvinyl alcohol.
}

contributed to AVM treatment. In this article, we review specific catheter and embolic techniques and the way in which concurrent advances in fluoroscopic techniques and angiographic suites have contributed to the evolution of this specialty.

\section{Catheters}

Many early attempts at catheterizing and embolizing blood vessels were made via an open surgical approach, which allowed direct puncture of aneurysms to facilitate electrothrombosis or galvanopuncture. ${ }^{17}$ Patients treated with these early extravascular approaches incurred many of the same complications and similar mortality rates as were associated with the open neurosurgical techniques used at the time. Furthermore, neurosurgical operating rooms were not equipped with the same fluoroscopic equipment as angiography suites, which made treatment much more cumbersome and time-consuming. Small, flexible catheters that can be advanced from distal sites have reduced the number of direct puncture embolizations and thus have reduced the number of separate craniotomies for direct embolization.

In 1964, Luessenhop and Velasquez ${ }^{21}$ reported catheterization of the external carotid artery for access to the ICA with a silastic-coated glass bulb. Through the glass bulb, they were able to gain access to the ICA and intracranial 


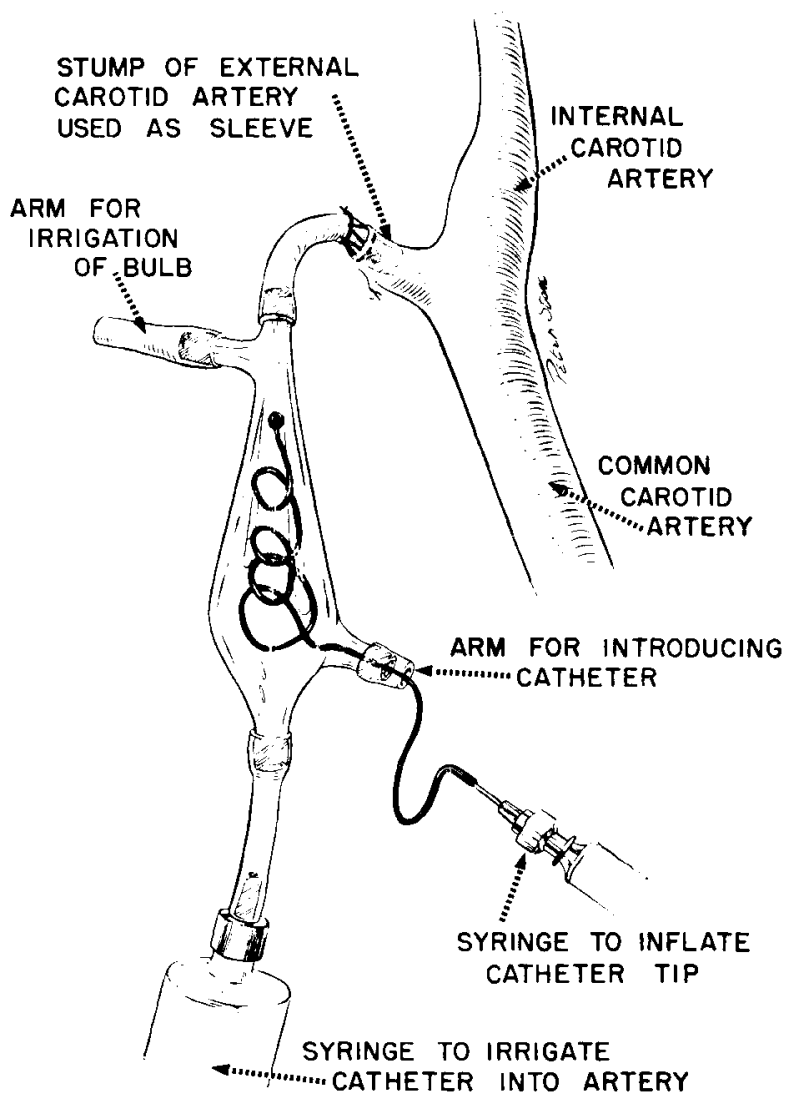

FIG. 1. Drawing showing a glass bulb and silastic catheter approach through the external carotid artery to gain access to the ICA circulation. (Reprinted with permission from Luessenhop AJ, Velasquez AC: Observations on the tolerance of the intracranial arteries to catheterization. J Neurosurg 21:85-91, 1964.)

vasculature (Fig. 1). Plastic and rubber catheters were tested in a dog model, and the resulting technique allowed a small embolus to carry a silastic tube of predetermined length into the distal carotid territory. In 1966, Frei, et al., ${ }^{9}$ introduced superselective catheterization with their paraoperational device catheter. The paraoperational device was introduced through an access catheter and then magnetically directed to the desired location. These authors proposed the use of an electrocautery tip attached to this device for coagulation of aneurysms.

Although Fogarty, et al., ${ }^{8}$ introduced balloon catheters in 1963 for thrombectomy, it was not until 1974 that Serbinenko ${ }^{24}$ described balloon catheterization and occlusion of intracranial vessels. For that system, a series of variably sized balloons was used to occlude flow in prominent vessels and to transport smaller balloons into collateral vessels. This technique depended on flow for balloon navigation and was limited by the size of the balloons, which were too large to reach the nidus. In 1972, Kerber and Newton described "the long tapered catheter" but found the intracranial circulation difficult to access. The addition of a balloon to the end of this device resulted in Kerber's ${ }^{18}$ description in 1976 of another flow-directed catheter, one with a calibrated leak balloon at the distal end. This silastic catheter and balloon enabled fourth- and fifth-order catheterizations to be performed. The balloon served a dual function by using a controlled leak to allow passage of contrast agent and cyanoacrylate embolic material through a single-lumen system. Nonetheless, overinflation of the balloon was associated with a high rate of vessel perforation (Fig. 2).

The second major type of catheter in use today is advanced over a torqueable guidewire system. Early guidewire designs did not achieve popularity and are poorly documented in the literature. Among the first designs, which were never widely marketed, were a 0.018 -in guidewire developed in 1974 by Tom Hutchins and a set of fine guidewires developed at Advanced Cardiovascular Systems (Santa Clara, CA). The first guidewire and catheter system to achieve mass production was the Tracker catheter system, which became available from Target Therapeutics (Fremont, CA) in 1986. This device provided the first alternative to balloon-directed catheters and spawned a new era in endovascular therapy (Kerber CW, personal communication, 2006). Guidewires are now available in a variety of strengths and diameters, which make them extremely versatile for endovascular treatment. The curve of the wire and catheter tips directly determine the steerability of the catheter.

Many catheters are now constructed of polyethylene, which is easily visualized on angiography. Other catheters and devices have radiopaque markers at their tips or at the working features of the catheter, and these markers aid navigation..$^{18}$ In 1975 , at the University of Pittsburgh, additional work began on visualizing the movement of catheters and guidewires. Commonly known as "road mapping," this technique allows a static subtracted image of the intracranial vessels to be used concurrently with the real-time fluoroscopic image. ${ }^{29}$ Different materials for catheters have also been developed, such as those that tolerate dimethyl sulfoxide ${ }^{14}$ and hydrophilic coatings. ${ }^{22}$ Vessels at branchpoints can be selected by shaping the ends of the catheters into tight or loose $\mathrm{J}$ shapes with steam or heat.

\section{Embolic Agents}

Early in the 1970s, Newton attempted to embolize paraspinal and upper-extremity AVMs with pellets from shotgun shells. This approach was fraught with complications and soon abandoned (Kerber CW, personal communication, 2006). In another early attempt to embolize an AVM, Luessenhop and Spence ${ }^{20}$ injected successively larger spherical emboli of methyl methacrylate $(2.5-4.2 \mathrm{~mm})$ until angiographic studies demonstrated no filling of the AVM and normal filling of other vessels. These emboli were injected directly into the bifurcation of the carotid artery and used the increased blood flow to the AVM to carry the emboli into the feeding vessels. The first patient they treated in this fashion suffered a temporary ischemic event, with normal strength returning at 7 weeks. The belief that higher flow in the vessels supplying the AVM can be used to direct emboli was the driving force behind catheter developments in the late 1960s and early 1970s.

The second AVM embolization reported by Luessenhop and Velasquez ${ }^{21}$ used their glass bulb cannulation technique. A silk suture attached to silastic emboli, which ranged from 2.5 to $3.5 \mathrm{~mm}$, depended on arterial flow to 


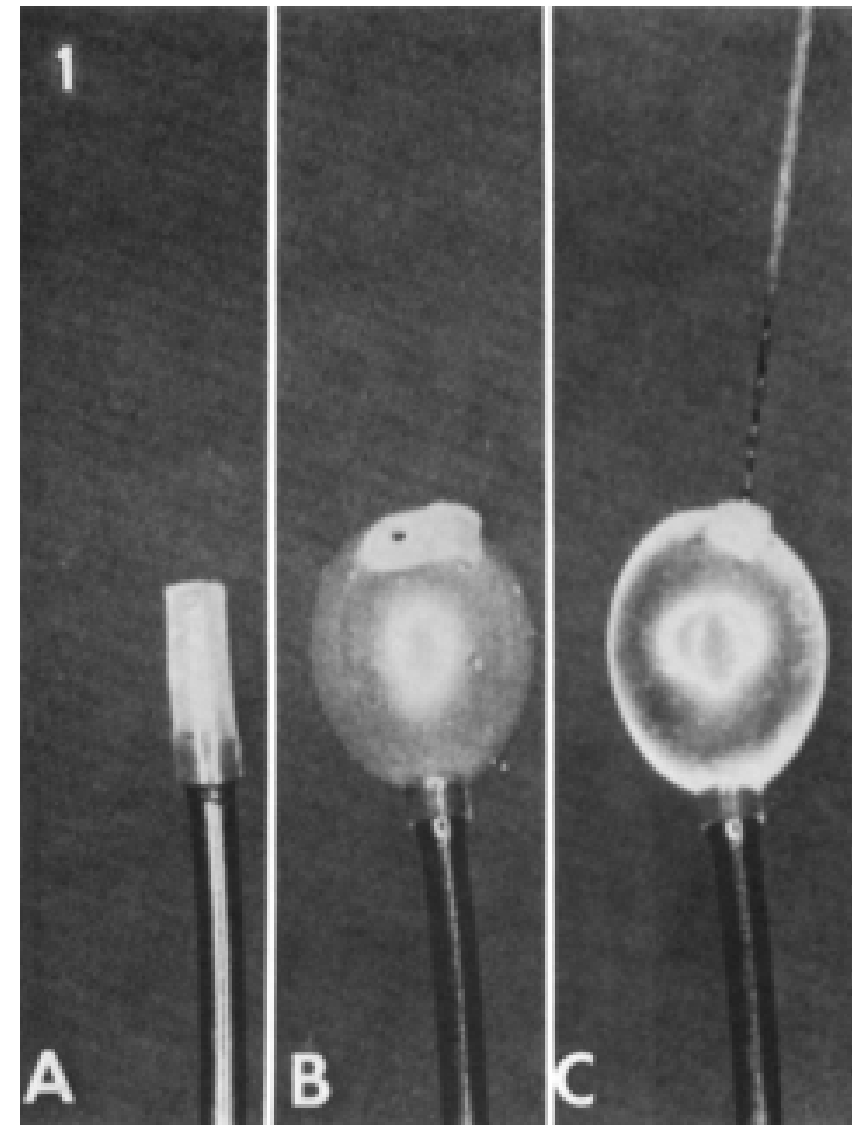

FIG. 2. Photographs showing silastic catheters with calibrated leak balloons used in navigating intracranial circulation and for embolization of intracranial lesions. (Reprinted with permission from the Radiological Society of North America. Kerber C: Balloon catheter with a calibrated leak. A new system for superselective angiography and occlusive catheter therapy. Radiology 120:547-550, 1976.)

draw the suture into the AVM. Angiographic studies demonstrated the changes in flow associated with different embolic locations, and the surgeons could decide whether to withdraw the emboli or cut the suture to release them into the lesion. Interestingly, these authors believed that flow reversal in the carotid artery by proximal compression was necessary before the catheters and the tethered emboli could be removed.

During the 1970s and 1980s, various materials were used as embolic agents: spherules of different materials, polymer threads, 6-0 silk sutures, gelatin particles, Avitene, and autologous clots. Many of these materials were difficult to control during delivery, were associated with high rates of recanalization, or caused vasculitis. Embolic techniques were also limited by the catheters available for delivery, and the rates of emboli reaching normal vessels were high. These complications led to the development of acrylic adhesives, which are the most popular embolic material today. ${ }^{23}$

One of the first tissue adhesives used as an embolic material was IBCA, ${ }^{2,18}$ which was first described in 1972 by Zanetti and Sherman ${ }^{31}$ for embolization of renal arteries and surgically constructed aneurysms in dogs. The
IBCA is injected through a microcatheter and rapidly polymerizes on contact with blood. Because of the rapidity of its polymerization, one of the earliest complications associated with this material was adhesion of the catheter within the feeding artery. According to several reports, retained catheters have been well tolerated; ${ }^{6}$ there are only a few reports of thrombotic or neurological deficits resulting from this complication.

As a response to the technical difficulties associated with IBCA, researchers developed NBCA. This newer material is superior to IBCA because it is easier to cut and the catheter is less prone to incorporation into the glue cast. As reported by Mathis, et al., ${ }^{22}$ in 1997, hydrophilic catheters were introduced concurrently. Effective use of NBCA requires practice and experience because it also polymerizes quickly. The polymerization rate is more variable than that of IBCA because the concentration of the material can be adjusted depending on the features of the lesion. Because it can be injected through a 25-gauge needle, NBCA was the agent most commonly used during direct intraoperative punctures.

In the 1980s, PVA particles, which can penetrate the nidus to different degrees, were reintroduced nearly 15 years after their initial development. ${ }^{13,19,27}$ The PVA particles are available in a variety of sizes, ranging from 150 to 1250 microns in diameter, and this substance appears to act by adhering to vessel walls. Furthermore, PVA requires no polymerization, and the risk of incorporating the catheter into the embolic cast is low. Nevertheless, because recanalization within 2 to 14 days has been reported, ${ }^{10,12,30}$ PVA is typically reserved for AVMs that will be resected within 1 to 2 days of embolization. Because of its affinity for vessel walls and other particles, PVA does not always completely penetrate smaller-diameter vessels. In an attempt to address this problem, microspheres were developed. These spherical, hydrophilic beads made of an acrylic copolymer are cross-linked with gelatin and have achieved better small-vessel penetration than PVA in some studies. ${ }^{3}$ Permanent occlusion and recanalization rates have yet to be published.

An agent first reported in 1990 is a combination of ethylene-vinyl alcohol copolymer and dimethyl sulfoxide that is marketed as Onyx (Onyx Liquid Embolic System; Micro Therapeutics, Inc., Irvine, CA). ${ }^{28}$ This material is thick enough to fill vessels but does not adhere to the catheter. Three concentrations are available to permit a range of precipitation rates. A drawback of Onyx is the angiotoxicity of dimethyl sulfoxide; therefore, reflux must be prevented during injection. However, enhancing the endothelial injury of the lesion itself can be beneficial. Although this material is still being investigated, Onyx has received favorable reviews from surgeons for use during resection. ${ }^{14}$

Other agents in the armamentarium of AVM treatment include ethanol and platinum coils. Ethanol is typically used to embolize tumors. It is easily introduced through flow-directed catheters and lets the practitioner avoid the complications associated with glues. The mechanism of action is a cytotoxic, ischemic injury resulting in vessel necrosis. Ethanol is also extremely toxic to normal tissues, can be painful in an awake patient, and has been known to induce seizures during embolization. The distribution of ethanol can be difficult to control, and therefore use of this 
substance has been largely abandoned. Platinum coils, the mainstay of endovascular intracranial aneurysm treatment, are useful for occlusion of larger feeding vessels, arteriovenous fistulas, and select features of AVMs.

Concurrently with other advances in embolic materials and catheters, the advent of nonionic, water-soluble contrast agents improved endothelial tolerability. The firstgeneration agent, metrizamide, was rapidly replaced with second-generation iohexol, which is still in use today. ${ }^{1,25}$ With iohexol, patients experienced fewer side effects and there was less hemodynamic instability following contrast injection. However, the incidence of thromboembolic side effects increased with the use of nonionic agents and necessitated the addition of heparin to the contrast material. This practice is now standard.

\section{Treatment Goals}

Early authors addressed issues such as achieving a cure for AVMs through embolization alone and partial embolization of unresectable lesions to reduce the risk of bleeding. ${ }^{5}$ In recent years, much debate has ensued about the appropriate role of embolization. Angiographically confirmed obliteration is the ultimate goal, but it is often difficult to obtain because many small feeding vessels cannot be catheterized. A cure is only achieved in 5 to $14 \%$ of patients, ${ }^{4,11}$ most of whom have small lesions. The benefits of embolizing AVMs as a preoperative treatment are well known. ${ }^{715}$ In appropriately selected patients, preoperative embolization can reduce the size of an AVM, eliminate surgically inaccessible vessels, and decrease intraoperative blood loss. Staged embolizations can be performed to limit the complications related to sudden alterations in flow dynamics. Rigorous postoperative control of blood pressure can help avoid potential perfusion pressure breakthrough. ${ }^{26}$ Routine neurological assessments in an intensive care setting and follow-up neuroimaging are recommended after embolization.

Cost-effectiveness analysis found a 9 to $34 \%$ cost reduction associated with the combined use of endovascular and open surgical approaches compared with surgery alone. ${ }^{16}$ At our institution, preoperative embolization is routine for Grade III AVMs and is often recommended for Grade II lesions. We recommend treatment for Grades IV and $\mathrm{V}$ lesions only in carefully selected patients.

Embolization can also be used in conjunction with radiosurgery. The goals of this procedure differ from microsurgical goals. Before open surgery, the goals are to embolize the nidus and large feeding vessels to facilitate resection. Before radiosurgery, embolization eliminates diffuse vessels at the perimeter of the lesion or can be used to address high-risk features such as aneurysms. This goal is particularly important for patients in whom hemorrhages occurred before radiosurgery could be performed. These treatments decrease the size of the radiation field needed and improve conformal dosing.

\section{Conclusions}

Although endovascular technology has advanced significantly over the last 40 years, it is still in its infancy. The future promises further developments that will im- prove the safety and efficacy of therapy to optimize minimally invasive approaches for the treatment of AVMs.

\section{References}

1. Aulie A: Effect of iohexol, metrizamide and ioxaglate on the blood-brain barrier. Acta Radiol Suppl 362:13-16, 1980

2. Bank WO, Kerber CW, Cromwell LD: Treatment of intracerebral arteriovenous malformations with isobutyl 2-cyanoacrylate: initial clinical experience. Radiology 139:609-616, 1981

3. Bendszus M, Klein R, Burger R, et al: Efficacy of trisacryl gelatin microspheres versus polyvinyl alcohol particles in the preoperative embolization of meningiomas. AJNR Am J Neuroradiol 21:255-261, 2000

4. Cockroft KM, Hwang SK, Rosenwasser RH: Endovascular treatment of cerebral arteriovenous malformations: indications, techniques, outcome, and complications. Neurosurg Clin $\mathbf{N}$ Am 16:367-380, 2005

5. Cromwell LD, Harris AB: Treatment of cerebral arteriovenous malformations. A combined neurosurgical and neuroradiological approach. J Neurosurg 52:705-708, 1980

6. Debrun GM, Aletich VA, Shownekeen H, et al: Glued catheters during embolization of brain AVMs with acrylic glue. Int Neuroradiol 3:12-19, 1997

7. DeMeritt JS, Pile-Spellman J, Mast H, et al: Outcome analysis of preoperative embolization with $N$-butyl cyanoacrylate in cerebral arteriovenous malformations. AJNR Am J Neuroradiol 16:1801-1807, 1995

8. Fogarty TJ, Cranley JJ, Kraus RJ, et al: A method for extraction of arterial emboli and thrombi. Surg Gynecol Obstet 116: 241-244, 1963

9. Frei EH, Driller J, Neufeld HN, et al: The POD and its applications. Med Res Eng 5:11-18, 1966

10. Germano IM, Davis RL, Wilson CB, et al: Histopathological follow-up study of 66 cerebral arteriovenous malformations after therapeutic embolization with polyvinyl alcohol. J Neurosurg 76:607-614, 1992

11. Gobin YP, Laurent A, Merienne L, et al: Treatment of brain arteriovenous malformations by embolization and radiosurgery. J Neurosurg 85:19-28, 1996

12. Guterman LR, Standard SC, Ahuja A, et al: Vascular and endovascular neurosurgery. Curr Opin Neurol 6:854-859, 1993

13. Horton JA, Marano GD, Kerber CW, et al: Polyvinyl alcohol foam-Gelfoam for therapeutic embolization: a synergistic mixture. AJNR Am J Neuroradiol 4:143-147, 1983

14. Howington JU, Kerber CW, Hopkins LN: Liquid embolic agents in the treatment of intracranial arteriovenous malformations. Neurosurg Clin N Am 16:355-363, 2005

15. Jafar JJ, Davis AJ, Berenstein A, et al: The effect of embolization with N-butyl cyanoacrylate prior to surgical resection of cerebral arteriovenous malformations. J Neurosurg 78:60-69, 1993

16. Jordan JE, Marks MP, Lane B, Steinberg GK: Cost-effectiveness of endovascular therapy in the surgical management of cerebral arteriovenous malformations. AJNR Am J Neuroradiol 17:247-254, 1996

17. Kanaan Y, Kaneshiro D, Fraser K, et al: Evolution of endovascular therapy for aneurysm treatment. Historical overview. Neurosurg Focus 18: E2, 2005

18. Kerber C: Balloon catheter with a calibrated leak. A new system for superselective angiography and occlusive catheter therapy. Radiology 120:547-550, 1976

19. Kerber CW, Bank WO, Horton JA: Polyvinyl alcohol foam: prepackaged emboli for therapeutic embolization. AJR Am J Roentgenol 130:1193-1194, 1978

20. Luessenhop AJ, Spence WT: Artificial embolization of cerebral arteries: report of use in a case of arteriovenous malformation. JAMA 172:1153-1155, 1960 
21. Luessenhop AJ, Velasquez AC: Observations on the tolerance of the intracranial arteries to catheterization. J Neurosurg 21: 85-91, 1964

22. Mathis JM, Evans AJ, DeNardo AJ, Kennett K, Crandall JR, Jensen ME, Dion JE: Hydrophilic coatings diminish adhesion of glue to catheter: an in vitro simulation of NBCA embolization. AJNR Am J Neuroradiol 18:1087-1091, 1997

23. O'Neill OR, Barnwell SL: Catheter systems and endovascular hardware, in Maciunas RJ (ed): Endovascular Neurological Intervention. Park Ridge, Ill: American Association of Neurological Surgeons, 1995, pp 43-58

24. Serbinenko FA: Balloon catheterization and occlusion of major cerebral vessels. J Neurosurg 41:125-145, 1974

25. Skalpe IO, Lundervold A, Tjorstad K: Cerebral angiography with non-ionic (metrizamide) and ionic (meglumine metrizoate) watersoluble contrast media. A comparative study with double blind technic. Neuroradiology 14:15-19, 1977

26. Spetzler RF, Wilson CB, Weinstein P, et al: Normal perfusion pressure breakthrough theory. Clin Neurosurg 25:651-672, 1978

27. Tadavarthy SM, Moller JH, Amplatz K: Polyvinyl alcohol (Ivalon) - a new embolic material. Am J Roentgenol Radium Ther Nucl Med 125:609-616, 1975
28. Taki W, Yonekawa Y, Iwata H, Uno A, Yamashita K, Amemiya $\mathrm{H}$ : A new liquid material for embolization of arteriovenous malformations. AJNR Am J Neuroradiol 11: $163-168,1990$

29. Turski PA, Stieghorst MF, Strother CM, et al: Digital subtraction angiography "road map." AJR Am J Roentgenol 139: 1233-1234, 1982

30. Viñuela F, Duckwiler G, Guglielmi G: Intravascular embolization of brain arteriovenous malformations, in Maciunas RJ (ed): Neurosurgical Topics: Endovascular Neurological Intervention. Park Ridge, IL: American Association of Neurological Surgeons, 1995, pp 189-199

31. Zanetti PH, Sherman FE: Experimental evaluation of a tissue adhesive as an agent for the treatment of aneurysms and arteriovenous anomalies. J Neurosurg 36:72-79, 1972

Manuscript received February 27, 2006.

Accepted in final form May 11, 2006.

Address reprint requests to: Felipe C. Albuquerque, M.D., c/o Neuroscience Publications, Barrow Neurological Institute, 350 West Thomas Road, Phoenix, Arizona 85013. email: neuropub@ chw.edu. 